\title{
PAPER
}

\section{Prediction of post-traumatic complaints after mild traumatic brain injury: early symptoms and biochemical markers}

\author{
J R de Kruijk, P Leffers, P P C A Menheere, S Meerhoff, J Rutten, A Twijnstra
}

J Neurol Neurosurg Psychiatry 2002;73:727-732

See end of article for authors' affiliations

.....................

Correspondence to: Dr J R de Kruijk, Department of Neurology, University Hospital

Maastricht, P Debeylaan 25, NL $6229 \mathrm{HX}$ Maastricht, Netherlands; jdk@sneu.azm.nl

Received

2 November 2001

In revised form 21 August

2002

Accepted 30 August 2002

Objectives: To identify parameters at first presentation after mild traumatic brain injury (MTBI) that are predictive of the severity of post-traumatic complaints (PTC) after six months. Early recognition of patients with MTBI who are at risk of developing PTC would be useful because early follow up at the outpatient clinic may help to reduce the severity of these complaints in the long run.

Methods: The presence of symptoms in the emergency room (ER) (headache, dizziness, nausea, vomiting, and neck pain) and biochemical markers (neurone specific enolase and S-100B) in serum were assessed as possible predictive variables for the severity of PTC. Outcome variables were the severity of 16 PTC six months after the trauma.

Result: After six months, the severity of most complaints had declined to pretrauma levels but medians for headache, dizziness, and drowsiness were still increased. In a series of 79 patients, 22 (28\%) reported one or more PTC after six months. After adjustment for baseline variables, an at least twofold increased severity of all PTC subgroups was reported by those patients reporting headache, dizziness, or nausea in the ER. A twofold increased severity of "cognitive" and "vegetative" PTC was also found in those with increased concentrations of biochemical serum markers at first presentation. The prevalence of full recovery after six months increased from $50 \%$ in patients with three symptoms to $78 \%$ in those with no symptoms in the ER. Inclusion of biochemical markers showed that all 10 patients with no symptoms in the ER and normal markers recovered fully.

Conclusions: The presence of headache, dizziness, or nausea in the ER after MTBI is strongly associated with the severity of most PTC after six months. Identifying MTBI patients in the ER without headache, dizziness, nausea, or increased serum marker concentrations may be a promising strategy for predicting a good outcome.

M ild traumatic brain injury (MTBI) accounts for about $90 \%$ of traumatic brain injuries. ${ }^{1-3}$ Historically, studies of traumatic brain injury have been difficult to compare because the terms "traumatic brain injury "and "head injury" have often been used synonymously. Both are the result of contact or acceleration-deceleration trauma of the head. However, only traumatic brain injury is associated with loss of consciousness, post-traumatic amnesia, and focal neurological signs. The usual diagnostic criterion for MTBI has been a Glasgow coma scale (GCS) score of 13 to $15 .{ }^{4}$ Terms such as commotio cerebri, concussion, and mild head injury have also been used. On the basis of more recent studies evaluating the association of GCS scores with the presence of intracerebral contusions on computed tomograms and with long term outcome, however, it has been suggested that the term MTBI should be limited to cases of short post-traumatic amnesia or loss of consciousness at presentation and a GCS score of 15 (optimal) within six hours. ${ }^{5-8}$

\section{Post-traumatic complaints}

Although the mortality rate is negligible, the post-traumatic sequel after MTBI is appreciable. During the past decade, many disciplines have been involved in the evaluation of outcome after MTBI (table 1). While different outcome variables have been measured, most can be interpreted as posttraumatic complaints (PTC). These PTC comprise a large number of symptoms, including headache, dizziness, drowsiness, loss of memory, and concentration problems. It is believed that these complaints are caused by a combination of brain injury and psychological, emotional, and motivational factors. The severity of most PTC declines during the first three months but the prevalence of having any complaints six months after the trauma is still estimated to be $20-80 \% .^{5} 91617$

Educating patients at the outpatient clinic shortly after MTBI about the expected prognosis of possible complications may help to reduce the severity of PTC in the long run. ${ }^{18-20}$ Since many MTBI patients do not experience persistent PTC at all, reducing needless follow up would save money and prevent medicalisation of these mainly young and healthy people. Against this background, early recognition of patients who are not at risk of persistent PTC would be useful.

\section{Prediction of PTC}

MTBI patients have been studied to find prognostic indicators of PTC. ${ }^{217} 21$ It was found that female sex, more advanced age, and prior MTBI are associated with poor outcome. Apart from headache within 24 hours after MTBI, which is also associated with poorer outcome, ${ }^{217}$ no associations between presenting MTBI symptoms and outcome have been reported.

The predictive value of serum concentrations of the specific serum markers S-100B and neurone specific enolase (NSE) for the Glasgow outcome score after severe head injury has been established. ${ }^{22}{ }^{23}$ NSE and S-100B in serum and cerebrospinal fluid have been reported to be markers of cell damage in the human central nervous system. ${ }^{24}{ }^{25}$ NSE is an isoenzyme of

Abbreviations: ER, emergency room; GCS, Glasgow coma scale; MTBI, mild traumatic brain injury; NSE, neurone specific enolase; PTC, post-traumatic complaints; VAS, visual analogue scale 
Table 1 Studies evaluating outcome after mild traumatic brain injury (MTBI)

\begin{tabular}{|c|c|c|}
\hline Study (reference) & Measured outcome & Conclusion \\
\hline Thornhill et al $2000^{2}$ & Problem oriented questionnaire & $47 \%$ of MTBI patients disabled after one year \\
\hline Van der Naalt et al $1999^{\circ}$ & Head injury symptom checklist & $\begin{array}{l}\text { One in seven patients completely free of } \\
\text { complaints after one year }\end{array}$ \\
\hline Voller et al $1999^{10}$ & Neuropsychological examination and neuroimaging & $\begin{array}{l}\text { Functional impairment could be identified in } \\
\text { MTBI patients six weeks after the trauma }\end{array}$ \\
\hline Deb et al $1998^{11}$ & $\begin{array}{l}\text { Glasgow outcome scale, Edinburgh rehabilitation status scale, Barthel } \\
\text { index, mini-mental state examination and postconcussional symptoms }\end{array}$ & $\begin{array}{l}\text { Substantial proportion of MTBI patients } \\
\text { showed neuropsychiatric reliable problems }\end{array}$ \\
\hline Crawford et al $1996^{12}$ & Rivermead head injury follow up questionnaire & $\begin{array}{l}\text { Impairment could be measured three and six } \\
\text { months after MTBI }\end{array}$ \\
\hline Bohnen et al $1995^{13}$ & $\begin{array}{l}\text { Postconcussional complaints in subgroups out of many non-specific } \\
\text { symptoms }\end{array}$ & $\begin{array}{l}\text { MTBI patients reported more symptoms than } \\
\text { controls at one year }\end{array}$ \\
\hline Newcombe et al $1994^{14}$ & Neuropsychological tests & $\begin{array}{l}\text { No difference between MTBI patients and } \\
\text { controls at one month }\end{array}$ \\
\hline Levin et al $1987^{15}$ & Neurobehavioural tests and postconcussion symptoms & $\begin{array}{l}\text { No difference between MTBI patients and } \\
\text { controls at three months }\end{array}$ \\
\hline
\end{tabular}

enolase and is located mainly in neurones but also in smooth muscle fibres and adipose tissue. ${ }^{26} \mathrm{~S}-100$ is an acidic calcium binding protein found in the brain as the isoforms $S-100 \mathrm{~B}$ $(95 \%)$ and S-100A (5\%). ${ }^{24} \mathrm{~S}-100 \mathrm{~B}$ is found in high concentrations in glial cells and Schwann cells and is highly specific for lesions of the central nervous system. After brain tissue damage, increased concentrations of NSE and S-100B can be measured in peripheral blood serum. ${ }^{23}{ }^{27}$ Serum S-100B and NSE concentration peaks have been measured within six hours following traumatic brain injury and these concentrations seem to reflect the severity of the mechanical disruption of the brain tissue. ${ }^{22} 2829$ Serum S-100B concentrations shortly after severe brain injury correlate not only with radiological abnormalities and clinical parameters such as the GCS and Marshall classification but also with the Glasgow outcome scale. ${ }^{22}{ }^{30}$ An association between early serum NSE concentrations and survival after severe head injury has been found by Yamazaki et al. ${ }^{31}$ Woertgen et al found no association between NSE concentrations and the Glasgow outcome scale. ${ }^{22}$ In contrast to severe traumatic brain injury, not much is known about the pathophysiology and natural history of MTBI, whose pathophysiological mechanism is hypothesised to involve traumatically induced axonal damage. ${ }^{32}$ Biochemical markers confirming traumatically induced axonal damage may be helpful in measuring the severity of brain damage.

Increased NSE and S-100B serum concentrations were also recently found in MTBI patients within six hours after the trauma. ${ }^{2933}$ Although early increased S-100B and NSE concentrations in serum seem to predict neuropsychological dysfunction, ${ }^{35}{ }^{36}$ the relation between increased biochemical marker concentrations and PTC after MTBI has not been studied so far.

The aim of the present study was to identify symptoms and biochemical markers at first presentation after MTBI that are predictive of the severity of PTC six months later. To develop a clinically useful test to determine which MTBI patients do not require follow up at the outpatient clinic, we also tried to find a combination of variables that could predict a favourable outcome after six months.

\section{METHODS}

\section{Participants}

The study was conducted at the University Hospital Maastricht, the Netherlands, as part of an intervention study on the efficacy of bed rest after MTBI. ${ }^{37}$ The study was approved by the hospital's ethics committee and each patient provided written informed consent. Patients were eligible for this study if they were older than 15 years and presented to the emergency room (ER) within six hours after the trauma. MTBI was defined as a blunt blow to the head resulting in (a) GCS of 14 or 15 on presentation at the emergency department; (b) presence of post-traumatic amnesia (of less than one hour); (c) initial loss of consciousness lasting less than 15 minutes; and (d) absence of focal neurological signs. This definition results in a clear distinction from moderate traumatic brain injury and traumatic non-brain injury such as whiplash. It was derived from recent MTBI review literature. ${ }^{53}$ Patients were excluded if they suffered from multitrauma or acute alcohol intoxication or if there was a necessity for clinical observation. Patients with a history of traumatic brain injury, alcohol abuse or a psychiatric disorder were also excluded.

\section{Predictive variables}

The present study assessed the presence of symptoms at the ER (headache, dizziness, nausea, vomiting, and neck pain) and biochemical markers (NSE and S-100B) in serum taken within six hours after the trauma as possible predictive variables for the severity of PTC. Age, sex, and intervention (bed rest within 10 days after the trauma) were considered to be possible confounders.

\section{Outcome variables}

Outcome variables were the severity of 16 PTC six months after the trauma. Selection of these PTC was based on a study of Bohnen et al. ${ }^{13}$ Bohnen and colleagues investigated the pattern of behavioural and bodily complaints in MTBI patients and in matched non-concussed control subjects. A heterogeneous item pool questionnaire consisting of 41 items, both traditional PTC and functional, was completed by both patients and controls. Three subgroups of intercorrelated items were selected by means of factor analysis. Bohnen and colleagues defined these subgroups as "dysthymic", "vegetative", and "cognitive". Univariate analysis showed significant differences in the degree of symptom endorsement between patients and controls for 16 symptoms. In the present study we constructed a fourth subgroup ("physical"), comprising the six significant symptoms that did not belong to a specific subgroup in the study of Bohnen et al. The complaints assessed in the present study were very similar to the symptoms used in the Rivermead postconcussion symptoms questionnaire, which was developed and standardised by the Oxford Head Injury Service. ${ }^{12}{ }^{16}$ In the present study, PTC were measured on a visual analogue scales (VAS) with a range of $0-100 \mathrm{~mm}$. Using a VAS score allowed us to measure the severity of the complaints in detail, rather than merely determining the presence or absence of these complaints.

\section{Study design}

If patients fulfilled all admissibility criteria, a written and oral explanation of the study was given by the physician in 
Table 2 Patients' characteristics

\begin{tabular}{lll}
\hline & $\begin{array}{l}\text { Patients followed up at two } \\
\text { weeks }(\mathrm{n}=103)\end{array}$ & $\begin{array}{l}\text { Patients followed up at six } \\
\text { months }(\mathrm{n}=79)\end{array}$ \\
\hline $\begin{array}{l}\text { Demographic characteristics } \\
\text { Women (\%) }\end{array}$ & \\
Age range & 43 & 44 \\
$\quad$ (years) (mean 37.2, range 15-75) (\%) & \\
15-25 & 28 & 28 \\
$26-35$ & 20 & 16 \\
$36-45$ & 20 & 20 \\
$46-55$ & 16 & 18 \\
$56-65$ & 9 & 9 \\
$>65$ & 7 & 9 \\
Acute symptoms (\%) & 61 & 62 \\
Headache & 27 & 25 \\
Nausea & 18 & 15 \\
Dizziness & 17 & 15 \\
Neck pain & 6 & 6 \\
Vomiting & & 35 \\
Serum markers (n=89) & 40 & 34 \\
NSE $\geqslant 10 \mu g / l$ & \\
S-100B $\geqslant 0.3 \mu g / l$ & 38 & \\
\hline NSE, neurone specific enolase. & &
\end{tabular}

attendance (neurology resident) and consent was requested for participation in the study. The presence of headache, neck pain, nausea, vomiting, and dizziness was recorded at first examination. Blood samples for NSE and S-100B measurements were taken within six hours after the trauma. NSE and S-100B concentrations were measured using commercially available immunoluminometric assays (Pharmacia NSE RIA, Pharmacia \& Upjohn, Uppsala, Sweden and LIA-mat Sangtec 100, Sangtec Medical, Bromma, Sweden). NSE and S-100B serum concentrations were defined as increased if they were higher than, respectively, $10 \mu \mathrm{g} / \mathrm{l}$ and $0.3 \mu \mathrm{g} / \mathrm{l}^{29}{ }^{34}$ At the follow up sessions (two weeks and six months), all patients were questioned at the outpatient clinic about the severity of PTC. At the first follow up, patients were questioned not only about the severity of PTC at that moment but also about the severity of these complaints before the trauma.

\section{Statistical analysis}

Baseline data including demographics, acute clinical symptoms, and serum marker concentrations were summarised. Medians and 5th and 95th percentiles of VAS scores for all PTC were recorded for each follow up session. The sums of the VAS scores for the four subgroups of PTC after six months were also calculated. This was done by simply adding up the scores of each item in the subgroups. The interrelations between the severity levels of these four PTC subgroups were expressed as Spearman's correlation coefficients.

Associations between PTC after six months and possible predictive variables were estimated by multiple linear regression analysis, adjusting for sex, age, and type of bed rest advice after trauma. The summed VAS scores of the 4 PTC subgroups and the VAS scores on the five most relevant PTC were used as outcome variables. Because of their non-normal

\begin{tabular}{|c|c|c|c|}
\hline \multirow[b]{2}{*}{ Post-traumatic complaints } & \multicolumn{3}{|l|}{ VAS score } \\
\hline & $\begin{array}{l}\text { Before trauma* } \\
(n=103)\end{array}$ & Two weeks ( $n=103$ ) & Six months $(n=79)$ \\
\hline \multicolumn{4}{|l|}{ Cognitive (range 0-100) } \\
\hline Trouble concentrating & $0(0-50)$ & $6(0-92)$ & $1(0-80)$ \\
\hline Easily overwhelmed by problems & $0(0-45)$ & $0(0-48)$ & $0(0-66)$ \\
\hline Forgetful & $1(0-45)$ & $10(0-60)$ & $1(0-70)$ \\
\hline Cognitive sum (range 0-300) & $7(0-90)$ & $28(0-147)$ & $13(0-186)$ \\
\hline \multicolumn{4}{|l|}{ Vegetative (range 0-100) } \\
\hline Flushing easily & $0(0-53)$ & $0(0-41)$ & $0(0-20)$ \\
\hline Feeling short of breath & $0(0-55)$ & $0(0-63)$ & $0(0-52)$ \\
\hline Feeling faint & $0(0-59)$ & $0(0-59)$ & $0(0-53)$ \\
\hline Vegetative sum (range 0-300) & $6(0-98)$ & $11(0-186)$ & $5(0-82)$ \\
\hline \multicolumn{4}{|l|}{ Dysthymic (range $0-100$ ) } \\
\hline Depressed & $0(0-48)$ & $0(0-54)$ & $1(0-59)$ \\
\hline Drowsy & $0(0-43)$ & $13(0-94)$ & $3(0-90)$ \\
\hline Crying more easily & $0(0-41)$ & $0(0-51)$ & $0(0-19)$ \\
\hline Confused & $0(0-22)$ & $1(0-57)$ & $0(0-49)$ \\
\hline Dysthymic sum (range $0-400$ ) & $7(0-101)$ & $31(0-179)$ & $8(0-190)$ \\
\hline \multicolumn{4}{|l|}{ Physical (range 0-100) } \\
\hline Headache & $1(0-59)$ & $12(0-97)$ & $3(0-75)$ \\
\hline Dizziness & $0(0-32)$ & $12(0-95)$ & $3(0-60)$ \\
\hline Nausea & $0(0-14)$ & $0(0-58)$ & $0(0-26)$ \\
\hline Lightheadedness & $0(0-33)$ & $3(0-60)$ & $1(0-60)$ \\
\hline Paraesthesia of arm(s) & $0(0-29)$ & $0(0-53)$ & $1(0-62)$ \\
\hline Sleeping problems & $1(0-83)$ & $1(0-83)$ & $0(0-57)$ \\
\hline Physical sum (range 0-600) & $18(0-164)$ & $63(0-314)$ & $28(0-233)$ \\
\hline
\end{tabular}


Table 4 Spearman correlation coefficients for severity of post-traumatic complaints (PTC) after six months in four subgroups

\begin{tabular}{|c|c|c|}
\hline $\begin{array}{l}\text { Sum of VAS score } \\
\text { of: }\end{array}$ & $\begin{array}{l}\text { Cognitive } \\
\text { PTC }\end{array}$ & Vegetative PTC Dysthymic PTC \\
\hline Vegetative PTC & $R=0.68$ * & \\
\hline Dysthymic PTC & $\mathrm{R}=0.75^{*}$ & $\mathrm{R}=0.75^{*}$ \\
\hline Physical PTC & $R=0.67$ * & $R=0.72 *$ \\
\hline
\end{tabular}

distribution, these outcome scores were first transformed to their natural logarithms $(\ln ) . \alpha=0.05$ was used as the significance level for statistical testing.

Variables with a significant association with PTC were selected and predictive values for combinations of these symptoms were calculated. For this purpose, patients were divided into two groups, "fully recovered" and "not fully recovered", after six months. Patients were considered to be fully recovered when severity of PTC at six months was the same as before the trauma (or better). This was considered to be the case when the individual VAS scores of all PTC after six months were lower than the 95th percentiles of the pretraumatic VAS scores of all patients. If one or more VAS scores after six months were higher than the pretraumatic 95th percentile, outcome was defined as "not fully recovered". This method was chosen instead of individual change scores because preinjury severity of PTC relies on patients' late self assessment. It seems likely that such self assessment of severity of pretraumatic complaints is unreliable, especially if PTC persists.

\section{RESULTS}

\section{Patient characteristics and acute variables}

Between October 1996 and June 1999, approximately 1125 patients with MTBI were seen at the University Hospital Maastricht. ${ }^{3}$ One hundred and seven of these patients were enrolled in the study. The rest met the exclusion criteria, refused to be included, or were not asked by the attending specialist to participate. After two weeks, 103 patients showed up for follow up examination (96\%), versus 79 (74\%) after six months. Baseline variables were described for the 103 patients showing up after two weeks and the 79 patients showing up after six months (table 2). Slightly more men than women were included ( $57 \%$ v $43 \%)$ in the study. More than half of the patients $(61 \%)$ reported headache at the ER. Nausea, dizziness, neck pain, and vomiting were reported by $27 \%$, $18 \%$, $17 \%$, and $6 \%$, respectively. Eleven patients (13\%) did not consent to have blood samples taken in the ER. Eventually, serum markers were measured in 89 patients. NSE concentrations were increased in $40 \%$ of patients, while S-100B concentrations were increased in $38 \%$ of patients. Comparing patients showing up at two weeks and six months did not indicate selective loss to follow up.

\section{Outcome variables}

Table 3 summarises VAS scores of PTC after two weeks and six months. Forgetfulness, drowsiness, headache, dizziness, trouble concentrating, and lightheadedness were the severest complaints after two weeks. After six months, the severity of most complaints had declined to pretrauma levels, though medians for headache, dizziness, and drowsiness were still increased. Strong correlations were found between the sum scores of all PTC subgroups after six months (table 4).

\section{Associations between acute symptoms and outcome variables}

After adjustment for sex, age, and advised bed rest, linear regression analysis of ln sum VAS scores of the four PTC subgroups after six months showed an at least twofold increased sum VAS score for all PTC subgroups in those patients reporting headache, dizziness, or nausea at the ER (table 5). Twofold increased cognitive and vegetative sum VAS scores were found in those with, respectively, increased S-100B and NSE concentrations.

For patients reporting headache, dizziness, or nausea at the ER, linear regression analysis of ln VAS scores for five specific PTC (adjusted for sex, age, and advised bed rest) showed an at

Table 5 Associations between PTC (sum of VAS, scores in subgroups) and predictors in the emergency room

\begin{tabular}{lllll}
\hline & \multicolumn{3}{l}{ PTC subgroups after six months, exp B $(95 \% \mathrm{Cl})$} \\
\cline { 2 - 5 } Acute parameters & Cognitive & Vegetative & Dysthymic & Physical \\
\hline Dizziness & $3.8(1.1 \text { to } 12.8)^{*}$ & $2.6(0.8$ to 8.0$)$ & $3.3(0.9$ to 12.1$)$ & $3.2(0.9$ to 11.5$)$ \\
Headache & $2.1(0.9$ to 5.2$)$ & $2.9(1.3 \text { to } 6.5)^{*}$ & $3.1(1.2 \text { to } 7.9)^{*}$ & $3.2(1.3 \text { to } 16.0)^{*}$ \\
Nausea & $2.1(0.8$ to 5.6$)$ & $2.0(0.8$ to 5.0$)$ & $3.7(1.3 \text { to } 10.1)^{*}$ & $3.9(1.4 \text { to } 10.5)^{*}$ \\
Vomiting & $0.9(0.2$ to 5.3$)$ & $0.5(0.1$ to 2.4$)$ & $1.7(0.3$ to 11.4$)$ & $4.3(0.7$ to 26.8$)$ \\
Neck pain & $0.9(0.3$ to 3.1$)$ & $1.5(0.5$ to 4.8$)$ & $1.0(0.3$ to 3.76$)$ & $0.8(0.2$ to 2.9$)$ \\
Increased S-100 & $2.0(0.8$ to 5.0$)$ & $1.2(0.5$ to 2.8$)$ & $1.4(0.5$ to 3.7$)$ & $1.5(0.6$ to 4.0$)$ \\
Increased NSE & $1.6(0.5$ to 4.9$)$ & $2.0(0.8$ to 5.5$)$ & $1.3(0.4$ to 4.2$)$ & $1.4(0.5$ to 4.5$)$
\end{tabular}

$\mathrm{Cl}$, confidence interval; $\exp \mathrm{B}$, coefficient from linear regression analysis of In outcome variable (severity of PTC after six months) on acute parameters after adjustment for sex, age, and advised bed rest after trauma. ${ }^{*} p<0.05$ (two sided test).

Table 6 Associations between five specific, PTCs (sum of VAS scores) and predictors at first presentation with MTBI

\begin{tabular}{llllll}
\hline & \multicolumn{2}{l}{ Specific PTC after six months, $\operatorname{exp~B~}(95 \% \mathrm{Cl})$} & & \\
\cline { 2 - 6 } Acute parameters & Trouble concentrating & Forgetfulness & Dizziness & Headache \\
\hline Dizziness & $3.5(1.2 \text { to } 10.3)^{*}$ & $2.6(0.9$ to 7.1$)$ & $1.5(0.5$ to 4.3$)$ & $2.4(0.9$ to 6.4$)$ & $3.8(1.3 \text { to } 11.3)^{*}$ \\
Headache & $2.9(1.3 \text { to } 6.2)^{*}$ & $1.2(0.6$ to 2.5$)$ & $3.7(1.9 \text { to } 7.6)^{*}$ & $1.9(0.9$ to 3.9$)$ & $2.4(1.1 \text { to } 5.4)^{*}$ \\
Nausea & $2.6(1.1 \text { to } 6.3)^{*}$ & $1.3(0.6$ to 3.0$)$ & $3.1(1.4 \text { to } 6.8)^{*}$ & $2.8(1.3 \text { to } 6.1)^{*}$ & $3.7(1.3 \text { to } 10.1)^{*}$ \\
Vomiting & $0.8(0.2$ to 4.1$)$ & $0.8(0.2$ to 3.5$)$ & $6.8(1.6 \text { to } 29.0)^{*}$ & $1.6(0.4$ to 6.6$)$ & $1.8(0.4$ to 9.0$)$ \\
Neck pain & $0.8(0.3$ to 2.6$)$ & $1.1(0.4$ to 3.2$)$ & $0.6(0.2$ to 1.63$)$ & $0.8(0.3$ to 0.9$)$ & $1.0(0.3$ to 3.3$)$ \\
Increased S-100 & $1.2(0.5$ to 2.8$)$ & $2.2(1.0 \text { to } 4.9)^{*}$ & $1.2(0.5$ to 2.6$)$ & $1.2(0.6$ to 2.5$)$ & $1.0(0.4$ to 2.5$)$ \\
Increased NSE & $1.5(0.6$ to 4.0$)$ & $1.3(0.5$ to 3.2$)$ & $2.3(0.9$ to 5.6$)$ & $2.2(1.0 \text { to } 5.0)^{*}$ & $1.2(0.4$ to 3.3$)$ \\
\hline
\end{tabular}

${ }^{*} \mathrm{p}<0.05$ (two sided test). 
Table 7 Presence of symptoms in the emergency room as a diagnostic test for the presence of PTC six months after MTBI

\begin{tabular}{llll}
\hline $\begin{array}{l}\text { Number of symptoms* } \\
\text { in the emergency room }\end{array}$ & $\begin{array}{l}\text { Presence of } \\
\text { PTC22) }\end{array}$ & $\begin{array}{l}\text { Absence of } \\
\text { PTC }(n=57)\end{array}$ & $\begin{array}{l}\text { Full recovery } \\
(\%)\end{array}$ \\
\hline $3(n=8)$ & 4 & 4 & 50 \\
$2(n=13)$ & 5 & 8 & 62 \\
$1(n=31)$ & 7 & 24 & 77 \\
$0(n=27)$ & 6 & 21 & 78 \\
\hline
\end{tabular}

*Headache, nausea, and dizziness

least twofold increased severity of one or more PTC after six months (table 6). Vomiting was associated (sevenfold) only with dizziness. A twofold increased severity of forgetfulness, dizziness, or headache after six months was found in patients with increased early serum NSE or S-100B concentrations.

No correlation was found between neck pain at the ER and outcome after six months.

\section{Clinical tests to predict outcome}

Twenty two of 79 patients $(28 \%)$ were classified as not fully recovered after six months. We tested the clinical value of headache, dizziness, and nausea at the ER in predicting full recovery after six months. Vomiting was not included because only $6 \%$ of the patients suffered this symptom. The prevalence of full recovery increased from $50 \%$ to $78 \%$ as the number of symptoms at the ER decreased from three to zero (table 7). Because of the small numbers, we did not statistically analyse these data. When we included serum markers of 68 patients as additional variables, full recovery was predicted in all 10 patients with no symptoms and normal serum markers. Of the 58 remaining patients with one or more symptoms or increased serum markers at presentation, 39 (67\%) had no PTC at six months.

\section{DISCUSSION}

\section{Principal findings}

According to the criteria used in the present study, 28\% of patients were not recovered fully six months after an MTBI. The presence of headache, dizziness, or nausea at the ER after MTBI is strongly associated with the severity of most PTC after six months. The absence of these symptoms in combination with normal serum marker concentrations within six hours after the trauma seems highly predictive of full recovery after six months.

\section{Relation to other studies}

Using the same set of PTC, Bohnen et al reported that symptoms in $25 \%$ of patients persisted for up to six months. ${ }^{13}$ Other studies found that $20-80 \%$ of patients with MTBI did not recover completely within the first year after the trauma. ${ }^{29}{ }^{17}$ This huge variation probably reflects the different definitions of MTBI and the use of different outcome variables in these studies. Cut off points for the GCS used to define MTBI ranged from 13-15. Outcome variables used were PTC, neuropsychological test results, or both after the trauma.

Even though there was a strong association between the subgroups in severity of PTC, physical complaints scored highest. The finding that headache and dizziness are important specific PTC confirms the findings of previous studies. ${ }^{917} 193940$ Patients in the present study reported only marginally more forgetfulness and trouble concentrating after six months than before the trauma. These specific variables, however, were included in the analysis because they had been mentioned as important outcome variables in earlier studies. ${ }^{19} 394142$
It was shown that the presence of headache, nausea, and dizziness in MTBI patients at the ER is associated with the severity of PTC after six months. Though the presence of headache within 24 hours after the trauma has previously been described as a prognostic factor for outcome after MTBI, ${ }^{17}$ the relation with nausea and dizziness had not been reported before.

Vomiting was associated with only the subgroup of physical PTC. This seems to be due mainly to the strong association with dizziness. In the literature, a twofold increased risk of skull fractures has been reported for post-traumatic vomiting. ${ }^{43}$ However, no association between vomiting and severity of PTC has been described before. In our study, the relation between vomiting in the ER and dizziness after six months may be explained by the occurrence of peripheral vestibular injury (labyrinthal contusion).

Increased biochemical marker concentrations were significantly associated with only headache and forgetfulness after six months. The association of S-100B with the severity of forgetfulness seems to support earlier findings that increased $\mathrm{S}-100 \mathrm{~B}$ is predictive of poorer cognitive functioning. ${ }^{35} 36$ Increased NSE concentrations were positively associated with severity of dizziness and headache after six months. Posttraumatic headache is believed to be mainly muscle related. ${ }^{44}$ Therefore, the increased NSE concentrations may originate from damaged muscle tissue.

The presence of neck pain in the ER was not at all associated with PTC after six months. This finding is notable, since complaints reported after whiplash injuries without MTBI are generally similar to those found in the present study. ${ }^{45}$

\section{Strengths and weaknesses of the present study}

In the present study, MTBI was defined on the basis of the most recent literature ${ }^{586}$ and, as explained in the methods section, the outcome variables were virtually the same as those used in recent studies. ${ }^{12} 1316$

The number of patients in our study was lower than expected, given the large number of MTBI patients presenting at our hospital during the inclusion period. Since the rate of non-inclusion was caused mostly by work strain in the emergency department, it seems unlikely that the enrolled patients represented a selection of MTBI patients with a different outcome.

Although headache, nausea, and dizziness were strongly associated with severity of PTC after six months, half of the patients with a combination of these three symptoms in the ER still had PTC after six months, whereas the other half had fully recovered. The prevalence of full recovery increased further in patients reporting two symptoms $(62 \%)$ or one symptom $(77 \%)$. Patients reporting no symptoms in the ER had a $78 \%$ chance of full recovery. The negative predictive value increased to $100 \%$ when increased S-100B and NSE concentrations were added to the selection variables. All MTBI patients without increased serum markers or symptoms in the ER were free of PTC after six months. Although biochemical marker data were missing for 11 patients, this did not seem to explain this finding because slightly more patients in the "markers missing" group than in the "markers not missing" group recovered fully ( $81 \%$ and $64 \%$, respectively). Because of the small sample size in the study, the results of the clinical tests using the combination of symptoms and serum markers should be interpreted with caution. However, these results seem interesting enough to warrant larger studies.

Our choice not to base recovery status on individual change scores of PTC was supported by the fact that that $86 \%$ had one or more PTC at six months that were higher than their pretraumatic score (data not presented). This would have led to an unrealistically low number of recovered patients. Therefore, the chosen definition of "full recovery" seems the best of two admittedly non-ideal options. 
In this study the real life performance such as time off work or study was not examined although it is a very important subject. When designing the study we feared that interviewing patients about these aspects would influence the patients' scores on the severity of their PTC. For example, a patient who has not returned to work would probably have overestimated the severity of his or her headache if we had asked at the same follow up session whether or when he or she had returned to work.

\section{Implications for MTBI patients}

Identifying MTBI patients in the ER without headache, dizziness, nausea, and increased serum marker concentrations may be a promising strategy to reduce unnecessary follow up because these patients probably will not develop persistent PTC. However, these results should be verified in future studies.

\section{Authors' affiliations}

J R de Kruiik, A Twiinstra, Department of Neurology, University Hospital Maastricht, Maastricht, Netherlands

P Leffers, Department of Epidemiology, Maastricht University, Maastricht, Netherlands

P P C A Menheere, Department of Clinical Chemistry, University Hospital Maastricht

S Meerhoff, J Rutten, Maastricht University Medical School, Maastricht, Netherlands

Competing interests: I de Kruijk, P Menheere, and A Twiinstra have been reimbursed by BYK Netherland BV, the manufacturer of the S-100 essay, for attending two conferences. BYK Netherland BV is a division of Sangtec Medical Sweden.

\section{REFERENCES}

1 Kraus J, McArthur D, Silverman T, et al. Epidemiology of brain injury. In: Narayan R, Wilberger J, Povlishock J, eds. Neurotrauma. New York: McGraw-Hill; 1996:13-30.

2 Thornhill S, Teasdale G, Murray G, et al. Disability in young people and adults one year after head injury: prospective cohort study. $B M$ 2000;320: 1631-5

3 Meerhoff S, Kruijk de J, Rutten J, et al. De incidentie van traumatisch schedel- of hersenletsel in het adherentiegebied van het Academisch Ziekenhuis Maastricht in 1997. Ned Tijdschr Geneeskd 2000; 144:915-23.

4 Rimel R, Giordani B, Barth J, et al. Moderate brain injury: completing the clinical spectrum of brain trauma. Neurosurgery 1982;11:344-51.

5 Alexander M. Mild traumatic brain injury: pathophysiology, natural history, and clinical management. Neurology 1995;45:1253-60.

6 Culotta V, Sementilli M, Gerold K, et al. Clinicopathological heterogeneity in the classification of mild head injury. Neurosurgery 1996;38:245-50.

7 Gomez PA, Lobato RD, Ortega JM, et al. Mild head injury: differences in prognosis among patients with a Glasgow coma scale score of 13 to 15 and analysis of factors associated with abnormal $\mathrm{CT}$ findings. $\mathrm{Br}$ Neurosurg 1996; 10:453-60.

8 Ruff RM, Jurica P. In search of a unified definition for mild traumatic brain injury. Brain Inj 1999;13:943-52.

9 Van der Naalt J, Zomeren A, Sluiter W, et al. One year outcome in mild and moderate head injury: the predictive value of acute injury characteristics related to complaints and return to work. J Neurol Neurosurg Psychiatry 1999;66:207-13.

10 Voller B, Benke T, Benedetto K, et al. Neuropsychological, MRI and EEG findings after very mild traumatic brain injury. Brain Inj 1999:13:821-7.

11 Deb S, Lyons I, Koutzoukis C. Neuropsychiatric sequelae one year after a minor head injury. J Neurol Neurosurg Psychiatry 1998;65:899-902.

12 Crawford S, Wenden F, Wade D. The Rivermead head injury follow up questionnaire: a study of a new rating scale and other measures to evaluate outcome after head injury. J Neurol Neurosurg Psychiatry 1996:60:510-4.

13 Bohnen N, Wijnen G, Twijnstra A, et al. The constellation of late post-traumatic symptoms of mild head injury patients. J Neurol Rehabil 1995;9:33-9.

14 Newcombe F, Rabbitt P, Briggs M. Minor head injury: pathophysiological or iatrogenic sequelae? I Neurol Neurosurg Psychiatry 1994;57:709-16.

15 Levin H, Mattis S, Ruff R, et al. Neurobehavioral outcome following minor head injury: a three-center study. J Neurosurg 1987;66:234-43.
16 King S. Emotional, neuropsychological, and organic factors: their use in the prediction of persisting postconcussion symptoms after moderate and mild head injuries. J Neurol Neurosurg Psychiatry 1996;61:75-81.

17 Rutherford W. Postconcussion symptoms: relation to acute neurological indices, individual differences, and circumstances of injury. In: Levin HS, Eisenberg HM, Benton AL, eds. Mild head injury. New York: Oxford University Press; 1989:217-40.

18 Paniak C, Toller-Lobe G, Reynolds S, et al. A randomized trial of two treatments for mild traumatic brain injury: 1 year follow up. Brain Inj 2000;14:219-26

19 Wade D, King N, Wenden F, et al. Routine follow up after head injury: a second randomised trial. J Neurol Neurosurg Psychiatry 1998:65:177-83

20 Minderhoud J, Boelens M, Huizinga J, et al. Treatment of minor head injuries. Clin Neurol Neurosurg 1980;82:127-40.

21 Hanlon RE, Demery JA, Martinovich Z, et al. Effects of acute injury characteristics on neurophysical status and vocational outcome following mild traumatic brain injury. Brain Inj 1999;13:873-87.

22 Woertgen C, Rothoerl D, Holzschuh M, et al. Comparison of serial S-100 and NSE serum measurements after severe head injury. Acta Neurochir 1997;139:1161-5.

23 Raabe A, Menon D, Gupta S, et al. Jugular venous and arterial concentrations of serum S-100B protein in patients with severe head injury: a pilot study. J Neurol Neurosurg Psychiatry 1998;65:930-2.

24 Persson L, Hardemark HG, Gustafsson J, et al. S-100 protein and neuron-specific enolase in cerebrospinal fluid and serum: markers of cell damage in human central nervous system. Stroke 1987;18:911-8.

25 Lamers K, van Engelen B, Gabreels F, et al. Cerebrospinal neuron-specific enolase, S-100 and myelin basic protein in neurological disorders. Acta Neurol Scand 1995;92:247-51.

26 Kato K, Ishiguro Y, Suzuki F, et al. Distribution of nervous system-specific forms of enolase in peripheral tissues. Brain Res 1982;237:441-8.

27 Yamakami I, Yamaura A, Isobe I. Types of brain injury and regional cerebral blod flow assesed by $99 \mathrm{mTc}$-HMPAO SPECT. Neurol Med Chir (Tokyo) 1993;33:7-12.

28 Rothoerl R, Woertgen C, Holzhusch M, et al. S-100 serum levels after minor and major head injury. J Trauma 1998;45:765-7.

29 Skogseid I, Nordby H, Urdal P, et al. Increased serum creatine kinase BB and neuron specific enolase following head injury. Acta Neurochir (Wien) 1992;115:106-11.

30 Raabe A, Grolms C, Keller M, et al. Correlation of computed tomography findings and serum brain damage markers following severe head injury. Acta Neurochir (Wien) 1998;140:787-91.

31 Yamazaki Y, Yada K, Morri S, et al. Diagnostic significance of serum neoron-specific enolase and myelin basic protein assay in patients with acute head injury. Surg Neurol 1995;43:267-71.

32 Povlishock JT, Jenkins LW. Are the pathobiological changes evoked by traumatic brain injury immediate and irreversible? Brain Pathol 1995:5:415-26.

33 Ingebrigtsen T, Romner B, Trumpy J. Management of minor head injury the value of early computed tomography and serum protein S-100 measurements. J Clin Neurosci 1997;4:29-33.

34 de Kruijk J, Leffers P, Menheere P, et al. S-100B and neuron-specific enolase in serum of mild traumatic brain injury patients: a comparison with healthy controls. Acta Neurol Scand 2001;103:175-9.

35 Herrmann M, Curio N, Grubich C, et al. Release of biochemical markers of damage to neuronal and glial brain tissue is associated with short and long term neuropsychological outcome after traumatic brain injury. J Neurol Neurosurg Psychiatry 2001;70:95-100.

36 Ingebrigtsen T, Waterloo K, Jacobsen E, et al. Traumatic brain damage in minor head injury: relation of serum S-100 protein measurements to magnetic resonance imaging and neurobehavorial outcome. Neurosurgery 1999;45:468-75.

37 de Kruijk J, Leffers P, Meerhoff S, et al. Effectiveness of bed rest after mild traumatic brain injury: a randomised trial of no versus six days of bed rest. J Neurol Neurosurg Psychiatry 2002;73:167-72.

38 de Kruijk J. Diagnostic criteria and differential diagnosis of mild traumatic brain injury. Brain Inj 2001;15:99-107.

39 Evans RW. The postconcussion syndrome and the sequelae of mild head injury. Neurol Clin 1992;10:815-47.

40 Packard R, Ham L. Posttraumatic headache. J Neuropsychiatry Clin Neurosci 1994;6:229-36.

41 Harrington D, Malec J, Cicerone K, et al. Current perceptions of rehabilitation professionals towards mild traumatic brain injury. Arch Phys Med Rehabil 1993;74:579-86.

42 Van der Naalt J, Joffre M, Zomeren van A, et al. Computed tomography and magnetic resonance imaging in mild to moderate head injury: early and late imaging related to outcome. Ann Neurol 1999:46:70-7

43 Nee P, Hadfield J, Yates D, et al. Significance of vomiting after head injury. J Neurol Neurosurg Psychiatry 1999;66:470-3.

44 Packard R. Epidemiology and pathogenesis of post-traumatic headache. J Head Trauma Rehabil 1999;14:9-21.

45 Alexander $M$. In the pursuit of proof of brain injury damage after whiplash injury. Neurology 1998;51:336-40.

46 Nell V, Yates DW, Kruger J. An extended Glasgow coma scale (GCS-E) with enhanced sensitivity to mild brain injury. Arch Phys Med Rehabil 2000;81:614-7. 